\title{
Determinants of maternal role adaptation in mothers with preterm neonates
}

\author{
Zahra Bostani Khalesi ${ }^{1}$, Soheyla Mirzaii ${ }^{2}$, Enayatollah Homaei Rad ${ }^{1}$, Sepideh Panjalipour ${ }^{2}$, Sodabeh Kazemi ${ }^{3}$ \\ ${ }^{1}$ Social Determinants of Health Research Center, Guilan University of Medical Sciences, Rasht, Iran \\ ${ }^{2}$ Student Research Committee, Guilan University of Medical Sciences, Rasht, Iran \\ ${ }^{3}$ Reproductive Health Research Center, Department of Obstetrics \& Gynecology, Al-Zahra Hospital, School of \\ Medicine, Guilan University of Medical Sciences, Rasht, Iran
}

\begin{abstract}
Objective: Becoming a mother is an innate process, without any culture-dependent instruction. While it is a pleasant experience, it can sometimes be associated with problems resulted from baby caring. Preterm birth can be a challenge for the maternal role adaptation (MRA). Therefore, the present study was conducted to determine the maternal role adaptation in mothers with preterm neonates.
\end{abstract}

Methods: The present study is cross-sectional, with a sample including 114 mothers of preterm infants in the NICU. We collected the data using a two-section questionnaire. The first section was a demographic questionnaire and the second section was a standardized questionnaire? "Maternal role adaptation scale in mothers with preterm neonates admitted to neonatal intensive care units" (MRAS: NICU). We ran the statistical analysis using descriptive and inferential statistical methods with the SPSS 21 software.

Results: The total MRA score was strong in half of the participants. The participants had a university education, were employed and satisfied with their economic status, and had a high score on adaptation to the maternal role. There are different domains to the MRA, the highest score was allocated to the participation in care (56.24 \pm 0.13$)$, and the lowest score was allocated to growth and development (3.12 \pm 0.28$)$.

Conclusions: According to the results of this study, the most important factors associated with MRA are the mother's age, education, and economic satisfaction. Determining the factors related to the mothers' adoption of premature infants could increase the ability of mothers to cope with problems and negative emotions, and enhance the adoption of maternal roles.

Keywords: Adaptation, Mothers, Role, Infant, Premature

\section{INTRODUCTION}

One of the most important roles of a woman is the maternal role (Hadadi et al., 2011). Bearing a baby results in the acceptance of fundamental changes in cognitive, emotional, social, and behavioral functions (Bailey, 2010). This psychological change can be influenced by a woman's specific circumstance, beliefs and attitudes, economic, social status, fitness, and knowledge, as well as social and psychological conditions, and as she is more mature, she will adapt better (Sayah \& Hosaini Mojarad, 2011). Adaptation to the maternal role involves conceptualizing and establishing a responsible maternal role that is recognized by the creation of a new identity and the formation of maternal behaviors (Kearvell \& Grant, 2010). Generally, the transition to the maternal stage as a natural crisis presents significant adoption problems for most mothers, and is a significant issue for health care providers (Bailey, 2010). When the preterm birth occurs, additional stress adds to this crisis, which is exacerbated by the admission of the infant to the NICU (Holditch-Davis, 2007).

Preterm and low birth weight infants have needs that require intensive neonatal care. These infants not only require intensive care immediately after birth, but they also have a higher morbidity rate (Morey \& Gregory, 2012). The mothers of these infants are at risk for maladjustment (Heidari et al., 2013). The results of studies show that mothers of preterm infants have more difficulty than mothers of term infants in adjusting to their maternal roles (Lee et al., 2009; Forcada-Guex et al.,2011; Gogate, $2020)$. In the case of preterm birth, the process of adjusting to the developmental crisis of having a new infant and the situational crisis of having a preterm infant provides a variety of stressors for the new mother (Pyhälä et al., 2009). Hospitalization of the infant is a stressful issue that causes disorder in the emotional and interdependent association between mother and infant (Dashevsky, 2012). A mother's ability to adjust to the stressors is related to the nature of the stimuli and to the mother's existing mode of adaptation. In other words, the more preterm the infant, the more intense the stressors that affect the mother's existing mode of adaptation (Gogate, 2020). A mother whose infant is admitted to the NICU has limited opportunities to care and interact with the infant, and this delays the acquisition of the maternal role (Rajabi et al., 2018). Of course, previous studies have shown that maternal role adaptation is influenced by a number of factors, such as social support, prejudice (Khandan et al., 2018), and judgmental prevention, self-efficacy (Niknajad et al., 2012), and culture (negative reactions from the community) (Heydarpour et al., 2017).

Berkowitz (2005) also indicated that the maternal role in mothers of premature infants admitted to NICU, not only is influenced by the maternal social communication, but also affects it, and it seems there are still many unknown aspects about it that need more investigation.

Since successful adaptation to the maternal role results in self-esteem and the satisfaction of her abilities in caring and nurturing the child; and awareness of its related factors in mothers of preterm infants admitted to the NICU can improve the quality of postpartum care (Shin, 2004). The researchers decided to conduct a study aimed at determining the extent of maternal role adaptation in mothers with premature infants and its related factors.

\section{MATERIAL AND METHODS}

The present study is a descriptive analysis. The participants were 114 mothers of premature infants admitted to the NICU. The inclusion criteria included consent to participate in the study, reading and writing skills, aged 18 and over, without any mental disorders, living with spouse, first 
marriage, first maternal experience, single infant, premature (Preterm child born in 28-36 weeks gestational age), without any apparent abnormalities, and the reluctance of the mothers to continue participating in this study was the exclusion criteria.

The necessary information regarding the objectives of the study was explained to each participant. All participants signed a written consent, and their confidentiality and privacy were maintained. In addition, we considered ethical principles in data gathering and analysis.

Data were collected using a three Self-reported questionnaire, including demographics, the standardized tool: "Maternal role adaptation scale in mothers with preterm neonates admitted to neonatal intensive care units" (MRAS: NICU) and related factors. The demographic questions consisted of items regarding age, education, ethnicity, occupation, average monthly income, alcohol, drug use and smoking.

MRAS: NICU was developed by Heidarpour et al. The MRAS: NICU is a 32-item-scale, designed to measure maternal role adaptation. This scale consists of 6 domains, including participation in care (14 questions), self-efficacy (6 questions), distant mothering (3 questions), uncertainty (4 questions), Interaction (3 questions), growth and development (2 questions) that correspond to a 5-point Likert scale, ranging from " 1 " Strongly Disagree to " 5 " Strongly Agree. The score of each domain was calculated as the sum of the scores of the items in that domain, and the total score of the scale was calculated as the sum of the domain scores, then the scores were converted to percentages and classified in three levels: Poor (0-33\%), moderate $(34-66 \%)$ and strong $(67-100 \%)$. The mean for the full scale was used where the scores ranged from 1 to 5 . The higher scores indicated higher maternal role adaptations. The instrument reliability with Cronbach's alpha coefficient of 0.90 and its stability after re-test with correlation coefficient of 0.81 , were confirmed by Heidarpour et al. (2016).

Maternal role adaptations related factors included maternal factors (satisfaction of living with spouse, satisfaction with economic-welfare status, duration of marriage, participation in childcare, family and friends support for child care, family structure, awareness of the pregnancy process, childbirth, and parenting roles); paternal (Age, Ethnicity, Education, Occupation, Average Monthly Income); and infant factors (Age of Birth, Sex, Satisfaction of Child Sex, Birth Weight), Fertility history (planning for birth, infertility history, abortion history, and fetal death).

After data collection, data was inserted in SPPS version 21 , for determining the score of the" Maternal Adaptation" questionnaire as a whole, and we divided the domains' statistical indices including mean, mode, minimum, maximum and standard deviation.

\section{RESULTS}

The mean age of mothers and their husbands was $29.34(S D=6.06)$ and $31.11(S D=6.91)$ years old, respectively. Most of the mothers were housewives (60.5\%) and $40.4 \%$ were college graduates (40.4). Most of the fathers were self-employed (50.4\%) and had a Diploma (45.6\%).

As far as ethnicity of mothers is concerned, $94.73 \%$ were pf Guilanian ethnicity and $60.5 \%$ were housewives. $52.4 \%$ of the mothers were satisfied with their economic status. In case of neonatal sex, $55.26 \%$ had boys and $69.29 \%$ planned their pregnancy.

Table 1 shows the demographic characteristics of the participants.

The mean MRAS score: NICU was $118.77 \pm 3.31$. MRA in $45 \%$ of mothers was strong, $23 \%$ moderate and $32 \%$ poor.

In the six MRAS sub-scales: NICU, the mean scores in Participation in care $(M=56.24, S D=0.13)$; Self- efficacy
$(M=23.2, \quad S D=1.02) ; \quad$ Maternal distance $\quad(M=11.34$, $\mathrm{SD}=0.22)$; Uncertainty $(\mathrm{M}=14.61, \mathrm{SD}=1.41)$; Interaction $(M=10.26, S D=0.25)$; Growth and development $(M=3.12$, $\mathrm{SD}=0.28)$. Overall, the highest score of six sub-scales was Participation in care $(80.34 \%)$; and the lowest score was Growth and development (52\%) (Table2).

Table 3 shows the findings of the regression model in relation to investigating the association between different variables and the MRAS: NICU score.

According to the T-test, the gender of the infant (female or male), the Smoking (yes or no), mother's and ethnicity (Guilanian or Non-Guilanian) and according to the Analysis of Variance (ANOVA) test, father's job (unemployed, laborer, employee, farmer, self- employed) and mother's job (housewives, laborer, employee, farmer, self-employed) did not have a significant effect on the mean MRAS score: NICU. In addition, there was a significant correlation between the MRAS score: NICU and the mother's age, education, and economic satisfaction were significantly related to the MRA (Table 3).

\section{DISCUSSION}

The results of this study showed that mothers with higher education had higher maternal role adaptation scores. According to the results from the Heydarpour study, lack of adequate information on what happens after delivery following preterm birth is confusing to mothers (Heydarpour et al., 2017). Lee et al. concluded that the lack of knowledge of premature infant care is the most important challenge for mothers (Lee et al., 2009). Another study by Horst et al., reported that having knowledge and skills to care for mothers with premature babies was the first priority for these mothers (Hurst, 2001). Since mothers' educational levels were significantly associated with the increased knowledge on premature childcare, the findings of this study are consistent with other similar studies.

The results are indicative of the fact that employed mothers had a higher maternal adaptation score. Rezaei (2010) stated that employed women had higher self-esteem, which made coping with difficult conditions easier for them. In another study, Dashevesky considers a lack of self-esteem as a contributing factor to reduce maternal competence feelings (Dashevsky, 2012). Increasing self-esteem leads to greater satisfaction with the maternal role (Heidari et al., 2012). The obtained results are consistent with those from other studies.

The results of this study showed that mothers who were satisfied with their economic status had higher maternal role adaptation scores. According to the results from the study by Holden et al., a better economic status will increase the self-efficacy of preterm infants' mothers (Holden et al., 2018). The results of the Heydarpour study also showed that self-efficacy is among the main elements resulting in adaptation to the maternal role (Heydarpour et al., 2017). Mothers, who have higher self-efficacy, have an easier transition to the maternity phase, thereby causing their general health to be less exposed to threats (Russell, 2006). The results of this study are in line with those from the stated studies.

According to the results on the score of adaptation to the maternal role by domains, the highest score relates to maternal participation in childcare, and continued confidence accounts for the lowest score. Most of the mothers whose infants are admitted to intensive care, have to share their maternal role with nurses and other caregivers, and their opportunities for infant care are limited (Zareinejad et al., 2018). Since one of the important aspects of the infant-mother communication process is the active participation of the mother in the care of the infant, we must encourage, support mothers to begin taking care of their 


\begin{tabular}{|c|c|c|}
\hline \multicolumn{2}{|l|}{ Variable } & Result \\
\hline \multicolumn{2}{|l|}{ Mother's age $(\mu \pm S D)$} & $29.34 \pm 6.06$ \\
\hline \multicolumn{2}{|l|}{ Father's age $(\mu \pm S D)$} & $31.11 \pm 6.91$ \\
\hline Ethnicity $(\%, n)$ & $\begin{array}{l}\text { Guilanian } \\
\text { Non Guilanian }\end{array}$ & $\begin{array}{c}94.7(108 / 114) \\
5.3(6 / 114)\end{array}$ \\
\hline Mother's job $(\%, n)$ & $\begin{array}{l}\text { Housewives } \\
\text { Laborer } \\
\text { Employee } \\
\text { Farmer } \\
\text { Self- employed }\end{array}$ & $\begin{aligned} & 60.5(69 / 114) \\
& 3.5(4 / 114) \\
& 14.0(16 / 114) \\
& 6.2(7 / 114) \\
& 15.8(18 / 114) \\
&\end{aligned}$ \\
\hline Father's job $(\%, n)$ & $\begin{array}{l}\text { Unemployed } \\
\text { Laborer } \\
\text { Employee } \\
\text { Farmer } \\
\text { Self- employed }\end{array}$ & $\begin{array}{c}2.6(3 / 114) \\
14.0(16 / 114) \\
22.8(26 / 114) \\
10.6(12 / 114) \\
50.0(57 / 114)\end{array}$ \\
\hline Mother's education $(\%, \mathrm{n})$ & $\begin{array}{l}\text { Illiterate } \\
\text { Primary school } \\
\text { Secondary school } \\
\text { Diploma } \\
\text { University }\end{array}$ & $\begin{array}{c}6.1(7 / 114) \\
7.9(9 / 114) \\
12.3(14 / 114) \\
33.3(38 / 114) \\
40.4(46 / 114)\end{array}$ \\
\hline Father's education $(\%, \mathrm{n})$ & $\begin{array}{l}\text { Illiterate } \\
\text { Primary school } \\
\text { Secondary school } \\
\text { Diploma } \\
\text { University }\end{array}$ & $\begin{array}{c}6.1(7 / 114) \\
4.4(5 / 114) \\
9.6(11 / 114) \\
45.6(52 / 114) \\
34.3(39 / 114)\end{array}$ \\
\hline Smoking $(\%, n)$ & $\begin{array}{l}\text { Yes } \\
\text { No }\end{array}$ & $\begin{array}{c}5.3(6 / 114) \\
94.7(108 / 114)\end{array}$ \\
\hline Economic satisfaction $(\%, n)$ & $\begin{array}{l}\text { Yes } \\
\text { No }\end{array}$ & $\begin{array}{l}52.4(63 / 114) \\
47.6(51 / 114)\end{array}$ \\
\hline
\end{tabular}

Table 2. Distribution of MRAS: NICU total and sub-scales

\begin{tabular}{|l|c|c|c|}
\hline $\begin{array}{l}\text { MRAS: NICU } \\
\text { Sub-scale }\end{array}$ & Range of Scores & Mean & Standard deviation \\
\hline Participation in care & $14-70$ & 56.24 & 0.13 \\
\hline Self- efficacy & $6-30$ & 23.2 & 1.02 \\
\hline Distance maternal & $3-15$ & 11.34 & 0.22 \\
\hline Uncertainty & $4-20$ & 14.61 & 1.41 \\
\hline Interaction & $3-15$ & 10.26 & 0.25 \\
\hline Growth and development & $2-6$ & 3.12 & 0.28 \\
\hline Total score & $32-160$ & 118.77 & $3 / 31$ \\
\hline
\end{tabular}

infants, and eventually take full responsibility for them (Bialoskurski et al., 2002). Results from the study by Ben-Ari et al. showed that mothers who did not play an active role in caring for their infants had a reduced maternal capacity to get adapted to maternal roles (Taubman-Ben-Ari et al., 2009). In the intensive care unit, mothers are often away from their babies, which, in turn, increases the mother's stress, whereas maternal support reduces stress (Neri et al., 2015). So, not only should nursing care focus on the treatment of the infant but also on the emotional support for the mother (Dezvaree et al., 2016). Meanwhile, the support of nurses and families increases the mother's self-confidence and suppresses her negative emotions (Khandan et al., 2018). Thus, nurses who are working in the neonatal intensive care unit should support and assure mothers to move into the maternity phase sooner.

\section{CONCLUSION}

Adaptation to the maternal role is a phenomenon that starts during pregnancy and continues after delivery. Mothers with preterm labor, face disorders in this process. Among the various factors, the mother's age, education, and economic satisfaction, increase adaptation to the maternal role. In so doing, providing appropriate information to mothers, social and emotional support for them, and through proper interaction between nurses and physicians with these mothers, an appropriate step can be taken to design effective interventions to increase adaptation to the maternal role in this group.

Due to the complexity of adaptation in parenthood, a mixed-method, including a quantitative and qualitative study is recommended, to determine the factors affecting MRA. 


\begin{tabular}{|c|c|c|c|c|c|}
\hline \multirow[t]{2}{*}{ Socio- individual variables } & \multicolumn{2}{|c|}{ Coefficients } & \multirow[t]{2}{*}{ p-value } & \multicolumn{2}{|c|}{$\begin{array}{c}\text { Coefficient of Confidence } \\
\text { Interval } 90 \%\end{array}$} \\
\hline & Coefficient & Standard deviation & & High & Low \\
\hline Fixed value & 27.58 & 0.11 & 0.00 & 38.54 & 16.61 \\
\hline Mother's age & -0.016 & 0.04 & 0.02 & 0.06 & -0.03 \\
\hline Mother's ethnicity & -1.06 & 1.4 & 0.44 & 1.71 & -3.85 \\
\hline Mother's education & -0.12 & 0.03 & 0.01 & 0.16 & -0.02 \\
\hline Mother's job & 0.24 & 0.2 & 0.23 & 0.65 & -0.16 \\
\hline Smoking & 1.27 & 1.43 & 0.37 & 4.11 & -1.56 \\
\hline Economic satisfaction & -0.21 & 0.16 & 0.02 & 0.5 & -1.05 \\
\hline Participation in care & 1.03 & 1.04 & 0.52 & 8.73 & -4.51 \\
\hline Father's age & -0.03 & 0.08 & 0.64 & 0.13 & -0.2 \\
\hline Father's education & -0.25 & 0.4 & 0.52 & 0.55 & -1.06 \\
\hline Father's job & 0.33 & 0.32 & 0.29 & 0.97 & -0.29 \\
\hline
\end{tabular}

\section{ACKNOWLEDGMENTS}

This study was extracted from a thesis of a doctorate degree in general practice (GP), approved by the Guilan University Ethics Committee (IR.GUMS.REC.1398.035). Guilan University of Medical Sciences, Rasht, Iran, supported this research. The authors extend their thanks to all the mothers who kindly participated in this study.

\section{CONFLICT OF INTEREST}

The authors declare that there is no conflict of interest.

\section{Corresponding Author:}

Zahra Bostani Khalesi

Social Determinants of Health Research Center

Guilan University of Medical Sciences

Rasht, Iran.

Email: z_bostani@yahoo.com

\section{REFERENCES}

Bailey S. Postnatal care: exploring the views of firsttime mothers. Community Pract. 2010; 83:26-9. PMID: 21214136

Berkowitz A. Parenting in the NICU: The process of role-making in maternal strategies for handling the care of ailing infants. Dissertation. Doctor of Philosophy in the Department of Sociology. Indiana University; 2005.

Bialoskurski MM, Cox CL, Wiggins RD. The relationship between maternal needs and priorities in a neonatal intensive care environment. J Adv Nurs. 2002;37:62-9. PMID: 11784399 DOI: 10.1046/j.1365-2648.2002.02057.x

Dashevsky A. An exploration of perceived maternal competence in mothers of healthy infants and in mothers of infants hospitalized at birth. PhD Dissertation. Massachusetts School of Professional Psychology; 2012.

Dezvaree N, Alaeekarahroudi F, KhanaliAgan L, TalebiGhane E. The Mother-Newborn's Attachment and Its Related Factors in Mothers of Hospitalized Preterm Neonates. J Health Care. 2016; 17: 340-9.
Forcada-Guex M, Borghini A, Pierrehumbert B, Ansermet F, Muller-Nix C. Prematurity, maternal posttraumatic stress and consequences on the mother-infant relationship. Early Hum Dev. 2011;87:21-6. PMID: 20951514 DOI: 10.1016/j.earlhumdev.2010.09.006

Gogate L. Maternal object naming is less adapted to preterm infants' than to term infants' word mapping. J Child Psychol Psychiatry. 2020;61:447-58. PMID: 31710089 DOI: $10.1111 /$ jcpp. 13128

Hadadi M, Kaldi A, Sajadi H, Salehi M. Association between job classification and mental health in employed women. Soc Welf. $2011 ; 11: 107-27$.

Heidari $\mathrm{H}$, Hasanpour M, Fooladi M. The Iranian parents of premature infants in NICU experience stigma of shame. Med Arh. 2012;66:35-40. PMID: 22482341 DOI: 10.5455/ medarh.2012.66.35-40

Heidari $H$, Hasanpour $M$, Fooladi $M$. The experiences of parents with infants in Neonatal Intensive Care Unit. Iran J Nurs Midwifery Res. 2013;18:208-13. PMID: 23983756

Heydarpour S, Keshavarz Z, Bakhtiari M, Zayeri F. Developing and Measuring Psychometric Properties of "maternal role adaptation instrument in mothers of preterm infants admitted to the neonatal intensive care unit". J Clin Res Paramed Sci. 2016; 5:e81495.

Heydarpour S, Keshavarz Z, Bakhtiari M. Factors Affecting Maternal Role Adaptation in Mothers of Preterm Infants Hospitalized in the Intensive Care Unit: A Qualitative Study. J Qual Res Health Sci 2017; 6: 134-46.

Holden L, Hockey R, Ware RS, Lee C. Mental health-related quality of life and the timing of motherhood: a 16-year longitudinal study of a national cohort of young Australian women. Qual Life Res. 2018;27:923-35. PMID: 29340901 DOI: $10.1007 / \mathrm{s} 11136-018-1786-7$

Holditch-Davis D. Outcomes of prematurity and neonatal intensive care unit care. J Obstet Gynecol Neonatal Nurs. 2007; 36:364-5. DOI: 10.1111/j.1552-6909.2007.00155.x 
Hurst I. Mothers' strategies to meet their needs in the newborn intensive care nursery. J Perinat Neonatal Nurs. 2001;15:65-82. PMID: 12095029 DOI: 10.1097/00005237-200109000-00006

Kearvell H, Grant J. Getting connected: How nurses can support mother/infant attachment in the neonatal intensive care unit. Aust J Adv Nurs. 2010; 27:75-82.

Khandan S, Riazi H, Akbari SAA, Nasiri M. The correlation between adaptation to the maternal role and social support in a sample of Iranian primiparous women. Adv Nurs Midwifery. $2018 ; 27: 37-42$.

Lee SN, Long A, Boore J. Taiwanese women's experiences of becoming a mother to a very-low-birth-weight preterm infant: a grounded theory study. Int J Nurs Stud. 2009;46:326-36. PMID: 19091313 DOI: 10.1016/j. ijnurstu.2008.10.004

Morey JA, Gregory K. Nurse-led education mitigates maternal stress and enhances knowledge in the NICU. MCN Am J Matern Child Nurs. 2012;37:182-91. PMID: 22549422 DOI: 10.1097/NMC.0b013e31824b4549

Neri E, Agostini F, Salvatori P, Biasini A, Monti F. Mother-preterm infant interactions at 3 months of corrected age: influence of maternal depression, anxiety and neonatal birth weight. Front Psychol. 2015;6:1234. PMID: 26388792 DOI: $10.3389 /$ fpsyg.2015.01234

Niknajad A, Ghojazadeh M, Sattarzadeh N, Bashar Hashemi F, Dezham Khoy Shahgholi F. Factors affecting the neonatal intensive care unit stay duration in very low birth weight premature infants. J Caring Sci. 2012;1:85-92. PMID: 25276681 DOI: $10.5681 /$ jcs.2012.013
Pyhälä R, Räikkönen K, Pesonen AK, Heinonen K, Hovi P, Eriksson JG, Järvenpää AL, Andersson S, Kajantie E. Behavioral inhibition and behavioral approach in young adults with very low birth weight-The Helsinki study of very low birth weight adults. Pers Individ Dif. 2009;46:106-10. DOI: 10.1016/j. paid.2008.09.013

Rajabi A, Maleki A, Dadashi M, Karami Tanha F. Evaluation of Maternal Role Adaptation in Mothers with Late-preterm Infants and its Related Factors . Prev Care Nurs Midwifery J. 2018; 8:110. DOI: $10.29252 /$ pcnm.8.1.1

Rezaei L. The effect of self-esteem on mental health in employed women working in Zimens factory and unemployed women. J Mod Ind. 2010;1:19-27.

Russell K. Maternal Confidence of First-time Mothers during their Child's Infancy. Dissertation. Georgia State University; 2006. Available at: https://scholarworks.gsu.edu/nursing_diss/1

Sayah M, Hosaini Mojarad A. The survey of maternal crisis in west world and its effects on Iranian community. Womens Strateg Stud. 2011;4:211-45.

Shin HJ. Situational meaning and maternal self-esteem in mothers with high risk newborn. Taehan Kanho Hakhoe Chi. 2004;34:93-101. PMID: 15314343 DOI: 10.4040/ jkan.2004.34.1.93

Taubman-Ben-Ari T, Shlomo SB, Sivan E, Dolizki M. The transition to motherhood-A time for growth. J Soc Clin Psychol. 2009;28:943-70.

Zareinejad S, Norouzi K, Saajedi F, Rahgooy A, Norouzi M, Hemmati A. Evaluation of the Relationship Between Self-efficacy and Quality of Life in Mothers With Preterm Infants in Kamali Hospital of Karaj, Iran, 2015. Iran J Rehabil Res Nurs. 2018; 4:54-61. 